\title{
Widespread horizontal transfer of the cerato-ulmin gene between Ophiostoma novo-ulmi and Geosmithia species
}

\author{
Priscilla P. BETTINI ${ }^{a, *}$, Arcangela FRASCELLA ${ }^{a, b}$, Miroslav KOLAŘíK ${ }^{c, d}$, \\ Cecilia COMPARINI ${ }^{b}$, Alessia L. PEPORI ${ }^{e}$, Alberto SANTINI ${ }^{e}$, Felice SCALA ${ }^{f}$, \\ Aniello SCALA ${ }^{b}$
}

\author{
a Dipartimento di Biologia, Università di Firenze, via Madonna del Piano 6, 50019 Sesto Fiorentino (FI), Italy \\ bipartimento di Scienze delle Produzioni Agroalimentari e dell'Ambiente (DISPAA), Università di Firenze, \\ via della Lastruccia 10, 50019 Sesto Fiorentino (FI), Italy \\ 'Institute of Microbiology of the Academy of Sciences of the Czech Republic (ASCR), v.v.i, Videnská 1083, \\ 14220 Praha 4, Czech Republic \\ ${ }^{\mathrm{d} D e p a r t m e n t}$ of Botany, Faculty of Science, Charles University, Benatská 2, 12801 Praha 2, Czech Republic \\ ${ }^{\mathrm{e}}$ Istituto per la Protezione delle Piante, Consiglio Nazionale delle Ricerche (IPP-CNR), via Madonna del Piano 10, \\ 50019 Sesto Fiorentino (FI), Italy \\ ${ }^{\mathrm{f} D i p a r t i m e n t o ~ d i ~ A r b o r i c o l t u r a, ~ B o t a n i c a ~ e ~ P a t o l o g i a ~ V e g e t a l e, ~ S e z i o n e ~ d i ~ P a t o l o g i a ~ V e g e t a l e, ~ U n i v e r s i t a ̀ ~ d i ~ N a p o l i ~}$ \\ "Federico II", via Università 100, 80055 Portici (NA), Italy
}

\section{A R T I C L E I N F O}

Article history:

Received 18 November 2013

Received in revised form

2 April 2014

Accepted 13 April 2014

Available online 30 April 2014

Corresponding Editor:

Brenda Diana Wingfield

\section{Keywords:}

Ascomycetes

Entomochoric fungi

Gene expression

Horizontal gene transfer

Hydrophobins

\begin{abstract}
A B S T R A C T
Previous work had shown that a sequence homologous to the gene encoding class II hydrophobin cerato-ulmin from the fungus Ophiostoma novo-ulmi, the causal agent of Dutch Elm Disease (DED), was present in a strain of the unrelated species Geosmithia species 5 (Ascomycota: Hypocreales) isolated from Ulmus minor affected by DED. As both fungi occupy the same habitat, even if different ecological niches, the occurrence of horizontal gene transfer was proposed. In the present work we have analysed for the presence of the cerato-ulmin gene 70 Geosmithia strains representing 29 species, isolated from different host plants and geographic locations. The gene was found in $52.1 \%$ of the strains derived from elm trees, while none of those isolated from nonelms possessed it. The expression of the gene in Geosmithia was also assessed by real time PCR in different growth conditions (liquid culture, solid culture, elm sawdust, dual culture with O. novo-ulmi), and was found to be extremely low in all conditions tested. On the basis of these results we propose that the cerato-ulmin gene is not functional in Geosmithia, but can be considered instead a marker of more extensive transfers of genetic material as shown in other fungi.
\end{abstract}

(c) 2014 The British Mycological Society. Published by Elsevier Ltd. All rights reserved.

\footnotetext{
* Corresponding author. Department of Biology, via Madonna del Piano 6, 50019 Sesto Fiorentino (FI), Italy. Tel.: +39 (055) 457 4741; fax: +39 (055) 4574905 .

E-mail addresses: p.bettini@unifi.it (P. P. Bettini), affabula@gmail.com (A. Frascella), mkolarik@biomed.cas.cz (M. Kolař́k), cecilia.comparini@unifi.it (C. Comparini), a.pepori@ipp.cnr.it (A. L. Pepori), a.santini@ipp.cnr.it (A. Santini), felice.scala@unina.it (F. Scala), aniello.scala@unifi.it (A. Scala). http://dx.doi.org/10.1016/j.funbio.2014.04.007
}

1878-6146/@ 2014 The British Mycological Society. Published by Elsevier Ltd. All rights reserved. 


\section{Introduction}

Horizontal gene transfer (HGT) involves the exchange of genetic information between phylogenetically distant organisms across the normal reproductive barriers. This phenomenon is common in prokaryotes where it is involved in the acquirement of traits such as antibiotic resistance, virulence, and metabolic abilities, enabling the colonization of new ecological niches and leading to the appearance of new species (Ochman et al. 2000). Because of the magnitude of HGT some authors have questioned the validity of the species concept in prokaryotes and have proposed that bacterial evolution should be described by means other than the standard tree of life (Ochman et al. 2000; Gogarten \& Townsend 2005; Boto 2010).

In recent years the increasing availability of whole genome sequences has allowed to appreciate HGT also in eukaryotes. Most documented cases involve the transfer of bacterial genes to unicellular eukaryotes where they have been proposed to play a role in adaptation processes (Andersson et al. 2003; Gojkovic et al. 2004; Ricard et al. 2006; Bowler et al. 2008; Schönknecht et al. 2013), but the transfer of genes from viral, bacterial or eukaryotic donors to plants and animals has also been described (reviewed in Keeling \& Palmer 2008; Bock 2010; Dunning Hotopp 2011). In filamentous fungi, in particular, HGT has been demonstrated in several instances and is involved in the acquirement of important characters such as virulence, leading in some cases to the emergence of new pathogens or of new host specificities for existing ones (Oliver \& Solomon 2008; Mehrabi et al. 2011; Gardiner et al. 2013). This is the case for the fungus Pyrenophora tritici-repentis whose ability to infect wheat has been related to the transfer of the gene encoding the host-selective toxin ToxA from the wheat pathogen Stagonospora nodorum (Friesen et al. 2006). In addition to the moving of single genes there is now evidence of more extensive transfers, involving gene clusters and whole chromosomes. A 23-gene cluster comprising the biosynthetic pathway for the production of the toxic metabolite sterigmatocystin has been horizontally transferred from Aspergillus nidulans to Podospora anserina, thus enriching the secondary metabolite repertoire of the recipient (Slot \& Rokas 2011). The transfer of whole chromosomes was also involved in the acquirement of pathogenicity by the tomato pathogens Alternaria alternata and Fusarium oxysporum f. sp. lycopersici (Akagi et al. 2009; Ma et al. 2010). Finally, Richards et al. (2011) showed how interkingdom gene transfer from filamentous fungi to oomycetes of at least 21 genes with roles in nutrient acquisition, degradation of plant surface components, and suppression of plant defences led to the appearance of plant pathogenic oomycetes.

Previous work demonstrated the presence in the Geosmithia species 5 (Ascomycota: Hypocreales) strain IVV7, isolated from Ulmus minor affected by Dutch Elm Disease (DED), of an 827 bp genomic fragment comprising the gene encoding the hydrophobin cerato-ulmin (cu) from Ophiostoma novo-ulmi (Bettini et al. 2010). The fungi of the genus Geosmithia are saprobes vectored by bark beetles infesting hardwoods and conifers worldwide. In particular, Geosmithia spp. cooccur regularly with phytopathogenic Ophiostoma species on elms or other trees (Kolařík et al. 2007, 2008; Kolařík \& Jankowiak 2013), occupying the same habitat even if different ecological niches. Continuous physical contact between organisms, as a consequence of habitat sharing, was suggested to be a favourable condition for the transfer of genetic material (Aguileta et al. 2009; Fitzpatrick 2012), therefore horizontal transfer of the cu gene between Geosmithia and Ophiostoma was proposed.

Hydrophobins are small hydrophobic proteins secreted by filamentous fungi. They are divided in two classes having similar functional characteristics: class I hydrophobins have been found in ascomycetes and basidiomycetes, while class II hydrophobins are present only in ascomycetes (Wösten 2001; Whiteford \& Spanu 2002). Both class I and class II hydrophobins have multiple roles in fungal growth and development, by taking part in the formation of aerial hyphae, fruiting bodies, microsclerotia, and microconidial chains (Fuchs et al. 2004; Yamada et al. 2005; Karlsson et al. 2007; Klimes et al. 2008), and in the maturation of the fungal cell wall (van Wetter et al. 2000). They are also important players in the establishment of relationships between fungi and other organisms, as in lichen-forming-ascomycetes (Scherrer et al. 2000), in ectomycorrhizal fungi (Mankel et al. 2002), and in host-pathogen interactions, where they can be the primary determinants of pathogenesis (Talbot 2003; Kim et al. 2005; Aimanianda et al. 2009).

Cerato-ulmin (CU) is a class II hydrophobin of about $8 \mathrm{kDa}$ present on the cell surface and/or excreted in culture by the phytopathogenic fungi Ophiostoma ulmi, O. novo-ulmi, and Ophiostoma himal-ulmi, and by the nonpathogen Ophiostoma quercus (Svircev et al. 1988; Scala et al. 1997; Carresi et al. 2008). Ophiostoma ulmi and O. novo-ulmi are responsible, respectively, for the first and the second DED pandemics that decimated elm populations in Europe, North America, and Asia since the last century. The first pandemic was caused in the early 1900 s by the nonaggressive, weakly pathogenic species O. ulmi, and the second, more severe, was caused since the early 1940s by the highly aggressive species O. novo-ulmi (Brasier \& Buck 2001). Ophiostoma novo-ulmi exists in two subspecies with different geographical origin: the typical form, also known as Eurasian race (hereafter as O. novo-ulmi only) and the North American race described as O. novo-ulmi subspecies americana (Brasier \& Kirk 2001). Both forms, including their hybrids, are present in Europe (Brasier \& Kirk 2010). The other DED species, O. himal-ulmi, was isolated in 1990s in the western Himalayas (Brasier \& Mehrotra 1995). It can be highly pathogenic on european elms, however no DED symptoms were detected on himalayan elms thus suggesting that the disease was at an endemically low level in this region. Ophiostoma quercus, on the other hand, is a widely distributed sapwood-staining fungus occurring on different hardwood hosts (Grobbelaar et al. 2009). When inoculated on elm trees it is able to colonize the plant without causing any appreciable alterations or disease symptoms (Sutherland et al. 1995; Del Sorbo et al. 2000).

For many years CU had been regarded as a virulence factor in DED pathogenesis (Takai 1974; Richards 1993; Del Sorbo et al. 2000), a view that has been challenged by the finding that pathogenicity of $\mathrm{O}$. novo-ulmi mutants unable to produce 
CU did not differ with respect to wild type strains (Brasier et al. 1995; Bowden et al. 1996; Tegli \& Scala 1996), and that overexpression of the $\mathrm{O}$. novo-ulmi cu gene in the less aggressive species O. ulmi did not increase the virulence of the latter (Temple et al. 1997). These results prompted some authors to propose that CU could be a factor involved in the fitness of DED pathogens, improving their ability to colonize and infect elm trees (Temple et al. 1997; Temple \& Horgen 2000). In fact, CU renders the Ophiostoma cell surface more hydrophobic, favouring the adhesion of the fungus to the insect vector and hence its dissemination and the spread of the disease; it also protects the fungus from dehydration (Temple et al. 1997; Temple \& Horgen 2000; Whiteford \& Spanu 2002).

In order to evaluate the magnitude of the HGT between 0 . novo-ulmi and Geosmithia spp., we performed an extensive search for the presence of the cu gene in a number of isolates of the genus Geosmithia derived from different host plants and geographic locations. The expression of the cu gene in Geosmithia was also assessed in varying growth conditions.

\section{Materials and methods}

\section{Fungal strains and culture}

Ophiostoma novo-ulmi isolate 182 (Carresi et al. 2008) and the Geosmithia strains, representing 29 different species, used in this study (Table 1), were maintained on Potato Dextrose Agar medium (BD Difco ${ }^{\top M}$ ). Plates were incubated in the dark at $24 \pm 1{ }^{\circ} \mathrm{C}$. For liquid culture, an agar plug was transferred to $100 \mathrm{ml}$ flasks containing $20 \mathrm{ml}$ of modified Takai medium (Scala et al. 1994). Flasks were wrapped in aluminium foil and incubated on a rotary shaker at $100 \mathrm{rpm}$ at $24 \pm 1{ }^{\circ} \mathrm{C}$. To recover the mycelium cultures were centrifuged (2500 rcf, $20 \mathrm{~min}$, room temperature) and pellets stored at $-20{ }^{\circ} \mathrm{C}$.

\section{DNA extraction and polymerase chain reaction (PCR)}

Genomic DNA extraction from mycelium was carried out with the NucleoSpin ${ }^{\circledR}$ Plant II kit (Macherey-Nagel GmbH \& Co. $\mathrm{KG})$. DNA concentration was evaluated with a Qubit ${ }^{\circledR} 2.0$ fluorometer (Invitrogen by Life Technologies) and PCR amplifications for both the cu gene and the ITS region of the rDNA cistron were carried out as described (Bettini et al. 2012). For the amplification of the cu gene the following primers, designed on the sequence of Ophiostoma novo-ulmi isolate 182 (GenBank accession no. KF725663), were used: 5'-AAATCTT CAAAATGCAGTTCTC-3' (forward) and 5'-AGAAGAATCGAAT GAAAACTTGATG-3' (reverse). Primers ITS1 and ITS4 (White et al. 1990) were used for the amplification of the ITS region of rDNA cistron.

\section{DNA sequencing and sequence analysis}

Sequencing of the amplified fragments was performed by Eurofins MWG Operon (Ebersberg, Germany) on either purified PCR products or on bands extracted from agarose gels (NucleoSpin ${ }^{\circledR}$ Gel and PCR Clean-up kit, Macherey-Nagel GmbH \& Co. KG). Sequences of the $\mathrm{cu}$ gene from Geosmithia were deposited in GenBank under accession numbers KF484882-KF484905.

GenBank homology searches were done with either blastn or blastx (Altschul et al. 1990) with default parameters. Alignments of the Geosmithia cu sequences with the cu gene sequences from Ophiostoma ulmi (GenBank accession nos. U23203 and Z80081), Ophiostoma novo-ulmi (GenBank accession nos. AJ295751, Z80082, Z80085, EU006082-EU006087), Ophiostoma himal-ulmi (GenBank accession nos. Z80083 and Z80084), Ophiostoma quercus (GenBank accession nos. EF447294, EF447295, EF447296), and Geosmithia sp. 5 strain IVV7 (GenBank accession no. DQ377561) were obtained using MAFFT version 6 (http://mafft.cbrc.jp/alignment/software/) (Katoh \& Toh 2008). The final dataset had 41 sequences and 459 characters, of which 179 were variable, 244 conservative and 23 singletons. Maximum Likelihood (ML) analyses were performed in PhyML 3.0 (Guindon et al. 2010), using Kimura2 parameter model and bootstrap support was obtained using 500 replicates. Evolutionary models were determined on datasets using MEGA 5.05 (Tamura et al. 2011). The cu gene sequences from $O$. quercus were selected as outgroup based on a preliminary Neighbour-Joining unrooted tree constructed using the most similar sequences in MEGA 5.05.

\section{RNA extraction and real time PCR}

Geosmithia sp. 5 strain IVV7 was grown as described in $100 \mathrm{ml}$ flasks containing $20 \mathrm{ml}$ of liquid modified Takai medium for 4 , $8,12,16$, and $20 \mathrm{~d}$. At each time-point cultures were centrifuged and pellets frozen at $-80{ }^{\circ} \mathrm{C}$. Three $4 \mathrm{~d}$-old Ophiostoma novo-ulmi isolate 182 liquid cultures were used as control. Strains from Geosmithia spp. 2, 5, 10, 13, 20, and Geosmithia langdonii were grown in the same conditions for $8 \mathrm{~d}$. For the induction experiments, Geosmithia sp. 5 strain IVV7 was grown for 4, 6, 8, and $12 \mathrm{~d}$ on $90 \mathrm{~mm}$ diameter Petri dishes either on elm sawdust medium (Baccelli et al. 2012) or in dual culture with 0 . novo-ulmi. To this aim $2 \times 10^{7}$ conidia of 0 . novo-ulmi in $50 \mu \mathrm{l}$ were inoculated on modified Takai medium and incubated at $24 \pm 1{ }^{\circ} \mathrm{C}$ in the dark. After $4 \mathrm{~d}$ of growth a sterile cellophane disk was placed onto each plate and a $6 \mathrm{~mm}$ diameter agar plug from a Geosmithia sp. 5 strain IVV7 solid culture was cut with a sterile cork-borer and placed in the centre of the plate. For each time-point at least six plates were prepared and incubated as described. Mycelium collected at each time-point was frozen at $-80^{\circ} \mathrm{C}$. As a control, Geosmithia sp. 5 strain IVV7 was grown on cellophane disks placed onto modified Takai solid medium plates.

Total RNA was extracted using the NucleoSpin ${ }^{\circledR}$ RNA Plant kit (Macherey-Nagel GmbH \& Co. KG). After the extraction a DNase digestion was performed (RQ DNase, Promega) followed by LiCl precipitation. RNA concentration was evaluated with a Qubit ${ }^{\circledR} 2.0$ fluorometer (Invitrogen by Life Technologies) and a PCR was carried out to ensure that the contaminant DNA had been removed by subjecting $500 \mathrm{ng}$ of total RNA to amplification with primers for the ITS region of the rDNA cistron. Conditions for PCR were as described in Section 2.2. Fivehundred nanogrammes of total RNA were then reverse transcribed (TaqMan Reverse Transcription Reagents, Applied Biosystems by Life Technologies). The amount of cu transcript was evaluated by means of real time PCR with TaqMan ${ }^{\circledR}$ 
Table 1 - Geosmithia species and strains used in the present study. Isolates identified by CCF code have been deposited in the Culture Collection of Fungi (Prague, Gzech Republic), while the others are deposited in the personal collections of A.L. Pepori (IPP-CNR, Sesto Fiorentino, Italy) and M. Kolařik (Institute of Microbiology of the ASCR, Prague, Czech Republic). Species numbering is from Kolař́k et al. (2007, 2008) and Kolařík \& Jankowiak (2013).

\begin{tabular}{|c|c|c|c|c|c|}
\hline Species & $\begin{array}{l}\text { Strain } \mathrm{N}^{\circ} \\
(\mathrm{CCF} \text { code) }\end{array}$ & Source & Geographic origin & Reference & $\begin{array}{c}\text { Presence of cu gene, } \\
\text { GenBank Acc. } \mathrm{N}^{\circ}\end{array}$ \\
\hline $\begin{array}{l}\text { Geosmithia } \\
\text { species } 1\end{array}$ & $\begin{array}{l}\text { MK1724 } \\
\text { (CCF3660) }\end{array}$ & $\begin{array}{l}\text { Xylocleptes bispinus on } \\
\text { Clematis vitalba }\end{array}$ & $\begin{array}{l}\text { Břeclav, Bulhary, Czech } \\
\text { Republic }\end{array}$ & $\begin{array}{l}\text { Kolařík et al. 2007, } \\
2008\end{array}$ & No \\
\hline $\begin{array}{l}\text { Geosmithia } \\
\text { species } 2\end{array}$ & $\begin{array}{l}\text { MK1623 } \\
\text { (CCF4273) }\end{array}$ & $\begin{array}{l}\text { Scolytus kirschii on Ulmus } \\
\text { minor }\end{array}$ & $\begin{array}{l}\text { Jorairatar, Andalusia, } \\
\text { Spain }\end{array}$ & $\begin{array}{l}\text { Kolařík et al. 2004, } \\
2008\end{array}$ & Yes, KF484882 \\
\hline $\begin{array}{l}\text { Geosmithia } \\
\text { species } 2\end{array}$ & MK1638 & $\begin{array}{l}\text { Scolytus multistriatus on } \\
\text { Ulmus minor }\end{array}$ & $\begin{array}{l}\text { Aracena, Andalusia, } \\
\text { Spain }\end{array}$ & $\begin{array}{l}\text { Kolař́k et al. 2004, } \\
2008\end{array}$ & No \\
\hline $\begin{array}{l}\text { Geosmithia } \\
\text { species } 2\end{array}$ & CNR39 & Ulmus minor & $\begin{array}{l}\text { Libický luh, Velký Osek, } \\
\text { Czech Republic }\end{array}$ & Pepori 2012 & No \\
\hline $\begin{array}{l}\text { Geosmithia } \\
\text { species } 2\end{array}$ & CNR40 & Ulmus minor & $\begin{array}{l}\text { Libický luh, Velký Osek, } \\
\text { Czech Republic }\end{array}$ & Pepori 2012 & Yes, KF484883 \\
\hline $\begin{array}{l}\text { Geosmithia } \\
\text { species } 2\end{array}$ & CNR42 & Ulmus glabra & $\begin{array}{l}\text { Rapatice, Pilsen, Czech } \\
\text { Republic }\end{array}$ & Pepori 2012 & Yes, KF484884 \\
\hline $\begin{array}{l}\text { Geosmithia } \\
\text { species } 2\end{array}$ & CNR45 & Ulmus laevis & $\begin{array}{l}\text { Dobřiň, Ústí nad Labem, } \\
\text { Czech Republic }\end{array}$ & Pepori 2012 & No \\
\hline $\begin{array}{l}\text { Geosmithia } \\
\text { species } 2\end{array}$ & CNR46 & Ulmus minor & $\begin{array}{l}\text { Jílové u Prahy, Žampach, } \\
\text { Sazava river, Czech } \\
\text { Republic }\end{array}$ & Pepori 2012 & Yes, KF484885 \\
\hline $\begin{array}{l}\text { Geosmithia } \\
\text { species } 2\end{array}$ & CNR54 & Ulmus glabra & $\begin{array}{l}\text { Hostenice, Usti nad } \\
\text { Labem, Czech Republic }\end{array}$ & Pepori 2012 & Yes, KF484886 \\
\hline $\begin{array}{l}\text { Geosmithia } \\
\text { species } 3\end{array}$ & $\begin{array}{l}\text { MK134 } \\
\text { (CCF3336) }\end{array}$ & $\begin{array}{l}\text { Scolytus rugulosus on } \\
\text { Malus domestica }\end{array}$ & $\begin{array}{l}\text { Opočno, Louny, Czech } \\
\text { Republic }\end{array}$ & $\begin{array}{l}\text { Kolař́k et al. 2004, } \\
2008\end{array}$ & No \\
\hline $\begin{array}{l}\text { Geosmithia } \\
\text { species } 4\end{array}$ & $\begin{array}{l}\text { MK1722 } \\
\text { (CCF4278) }\end{array}$ & $\begin{array}{l}\text { Pteleobius vittatus on } \\
\text { Ulmus laevis }\end{array}$ & $\begin{array}{l}\text { Břeclav, Kančí obora, } \\
\text { Czech Republic }\end{array}$ & Kolařík et al. 2008 & No \\
\hline $\begin{array}{l}\text { Geosmithia } \\
\text { pallida }\end{array}$ & CNR136 & $\begin{array}{l}\text { Elm clone U'FL634' } \\
\text { (IPP-CNR) }\end{array}$ & Ugnano (FI), Italy & Pepori 2012 & No \\
\hline $\begin{array}{l}\text { Geosmithia } \\
\text { species } 5\end{array}$ & IVV7 & $\begin{array}{l}\text { Ulmus minor tree } \\
\text { affected by DED }\end{array}$ & Vibo Valentia (RC), Italy & Bettini et al. 2010 & Yes, DQ377561 \\
\hline $\begin{array}{l}\text { Geosmithia } \\
\text { species } 5\end{array}$ & $\begin{array}{l}\text { MK445a } \\
\text { (CCF3477) }\end{array}$ & $\begin{array}{l}\text { Scolytus multistriatus on } \\
\text { Ulmus sp. }\end{array}$ & Louny, Czech Republic & $\begin{array}{l}\text { Kolařík et al. 2004, } \\
2008\end{array}$ & Yes, KF484887 \\
\hline $\begin{array}{l}\text { Geosmithia } \\
\text { species } 5\end{array}$ & MK971 & $\begin{array}{l}\text { Pteleobius vittatus on } \\
\text { Ulmus minor }\end{array}$ & $\begin{array}{l}\text { Milovický les, Bulhary, } \\
\text { Czech Republic }\end{array}$ & $\begin{array}{l}\text { Kolařík et al. 2004, } \\
2008\end{array}$ & No \\
\hline $\begin{array}{l}\text { Geosmithia } \\
\text { species } 5\end{array}$ & MK980 & $\begin{array}{l}\text { Pteleobius vittatus on } \\
\text { Ulmus laevis }\end{array}$ & $\begin{array}{l}\text { Kančí obora forest, } \\
\text { Břeclav, Czech Republic }\end{array}$ & $\begin{array}{l}\text { Kolařík et al. 2004, } \\
2008\end{array}$ & Yes, KF484888 \\
\hline $\begin{array}{l}\text { Geosmithia } \\
\text { species } 5\end{array}$ & $\begin{array}{l}\text { MK1550a } \\
\text { (CCF4271) }\end{array}$ & $\begin{array}{l}\text { Scolytus multistriatus on } \\
\text { Ulmus laevis }\end{array}$ & $\begin{array}{l}\text { Kančí obora forest, } \\
\text { Břeclav, Czech Republic }\end{array}$ & $\begin{array}{l}\text { Kolařík et al. 2004, } \\
2008\end{array}$ & No \\
\hline $\begin{array}{l}\text { Geosmithia } \\
\text { species } 5\end{array}$ & CNR28 & Ulmus minor & $\begin{array}{l}\text { Středokluky, Czech } \\
\text { Republic }\end{array}$ & Pepori 2012 & No \\
\hline $\begin{array}{l}\text { Geosmithia } \\
\text { species } 5\end{array}$ & CNR31 & Ulmus glabra & $\begin{array}{l}\text { Milá, Usti nad Labem, } \\
\text { Czech Republic }\end{array}$ & Pepori 2012 & Yes, KF484889 \\
\hline $\begin{array}{l}\text { Geosmithia } \\
\text { species } 5\end{array}$ & CNR33 & Ulmus minor & $\begin{array}{l}\text { Žabokliky, Usti nad } \\
\text { Labem, Czech Republic }\end{array}$ & Pepori 2012 & Yes, KF484890 \\
\hline $\begin{array}{l}\text { Geosmithia } \\
\text { species } 5\end{array}$ & CNR36 & Ulmus minor & $\begin{array}{l}\text { Jílové u Prahy, Žampach, } \\
\text { Czech Republic }\end{array}$ & Pepori 2012 & Yes, KF484891 \\
\hline $\begin{array}{l}\text { Geosmithia } \\
\text { species } 5\end{array}$ & CNR48 & Ulmus minor & $\begin{array}{l}\text { Libický luh, Velký Osek, } \\
\text { Czech Republic }\end{array}$ & Pepori 2012 & Yes, KF484892 \\
\hline $\begin{array}{l}\text { Geosmithia } \\
\text { putterillii }\end{array}$ & $\begin{array}{l}\text { U131a } \\
\text { (CCF4202) }\end{array}$ & $\begin{array}{l}\text { Phloeosinus sequoiae on } \\
\text { Sequoia sempervirens }\end{array}$ & Bohemian river, CA, USA & M.K., unpubl. & No \\
\hline $\begin{array}{l}\text { Geosmithia } \\
\text { flava }\end{array}$ & $\begin{array}{l}\text { MK264 } \\
\text { (CCF3354) }\end{array}$ & $\begin{array}{l}\text { Leperisinus fraxini on } \\
\text { Fraxinus excelsior }\end{array}$ & Muráň plain, Slovakia & Kolařík et al. 2004 & No \\
\hline $\begin{array}{l}\text { Geosmithia } \\
\text { species } 8\end{array}$ & $\begin{array}{l}\text { MK263 } \\
\text { (CCF4258) }\end{array}$ & $\begin{array}{l}\text { Scolytus intricatus on } \\
\text { Quercus dalechampii }\end{array}$ & $\begin{array}{l}\text { Šiance hill, Muráňská } \\
\text { planina, Slovakia }\end{array}$ & Kolařík et al. 2008 & No \\
\hline $\begin{array}{l}\text { Geosmithia } \\
\text { species } 9\end{array}$ & $\begin{array}{l}\text { RJ113k } \\
\text { (CCF4311) }\end{array}$ & $\begin{array}{l}\text { Cryphalus piceae on Abies } \\
\text { alba }\end{array}$ & Czajowice, Poland & $\begin{array}{l}\text { Kolařík \& } \\
\text { Jankowiak } 2013\end{array}$ & No \\
\hline $\begin{array}{l}\text { Geosmithia } \\
\text { species } 10\end{array}$ & $\begin{array}{l}\text { MK1788 } \\
\text { (CCF4286) }\end{array}$ & $\begin{array}{l}\text { Hypoborus ficus on Ficus } \\
\text { carica }\end{array}$ & Suvalan, Azerbaijan & $\begin{array}{l}\text { Kolařík et al. 2007, } \\
2008\end{array}$ & No \\
\hline $\begin{array}{l}\text { Geosmithia } \\
\text { species } 10\end{array}$ & $\begin{array}{l}\text { MK441 } \\
\text { (CCF3553) }\end{array}$ & $\begin{array}{l}\text { Scolytus multistriatus on } \\
\text { Ulmus minor }\end{array}$ & Louny, Czech Republic & $\begin{array}{l}\text { Kolařík et al. 2007, } \\
2008\end{array}$ & No \\
\hline $\begin{array}{l}\text { Geosmithia } \\
\text { species } 10\end{array}$ & $\begin{array}{l}\text { MK544 } \\
\text { (CCF4301) }\end{array}$ & $\begin{array}{l}\text { Pteleobius vittatus on } \\
\text { Ulmus species }\end{array}$ & $\begin{array}{l}\text { Kőris-hegy, Bakony } \\
\text { range, Hungary }\end{array}$ & $\begin{array}{l}\text { Kolarrík et al. 2007, } \\
2008\end{array}$ & No \\
\hline $\begin{array}{l}\text { Geosmithia } \\
\text { species } 10\end{array}$ & $\begin{array}{l}\text { MK989 } \\
\text { (CCF3560) }\end{array}$ & $\begin{array}{l}\text { Scolytus pygmaeus on } \\
\text { Ulmus minor }\end{array}$ & $\begin{array}{l}\text { Milovický les, Bulhary, } \\
\text { Czech Republic }\end{array}$ & $\begin{array}{l}\text { Kolař́k et al. 2007, } \\
2008\end{array}$ & No \\
\hline
\end{tabular}


Table 1 - (continued)

\begin{tabular}{|c|c|c|c|c|c|}
\hline Species & $\begin{array}{l}\text { Strain } \mathrm{N}^{\circ} \\
\text { (CCF code) }\end{array}$ & Source & Geographic origin & Reference & $\begin{array}{c}\text { Presence of cu gene, } \\
\text { GenBank Acc. } \mathrm{N}^{\circ}\end{array}$ \\
\hline $\begin{array}{l}\text { Geosmithia } \\
\text { species } 10\end{array}$ & $\begin{array}{l}\text { MK1508 } \\
\text { (CCF4269) }\end{array}$ & $\begin{array}{l}\text { Scolytus kirschii on Ulmus } \\
\text { minor }\end{array}$ & Termoli (CB), Italy & $\begin{array}{l}\text { Kolařík et al. 2007, } \\
2008\end{array}$ & No \\
\hline $\begin{array}{l}\text { Geosmithia } \\
\text { species } 10\end{array}$ & MK1703 & $\begin{array}{l}\text { Scolytus multistriatus on } \\
\text { Ulmus laevis }\end{array}$ & $\begin{array}{l}\text { Břeclav, Kančí obora } \\
\text { forest, Czech Republic }\end{array}$ & $\begin{array}{l}\text { Kolařík et al. 2007, } \\
2008\end{array}$ & No \\
\hline $\begin{array}{l}\text { Geosmithia } \\
\text { species } 10\end{array}$ & CNR8 & Ulmus laevis & $\begin{array}{l}\text { Libický luh, Velký Osek, } \\
\text { Czech Republic }\end{array}$ & Pepori 2012 & Yes, KF484894 \\
\hline $\begin{array}{l}\text { Geosmithia } \\
\text { species } 10\end{array}$ & CNR10 & Ulmus minor & $\begin{array}{l}\text { Jílové u Prahy, Žampach, } \\
\text { Czech Republic }\end{array}$ & Pepori 2012 & Yes, KF484895 \\
\hline $\begin{array}{l}\text { Geosmithia } \\
\text { species } 10\end{array}$ & CNR16 & Ulmus minor & $\begin{array}{l}\text { Libický luh, Velký Osek, } \\
\text { Czech Republic }\end{array}$ & Pepori 2012 & Yes, KF484896 \\
\hline $\begin{array}{l}\text { Geosmithia } \\
\text { species } 10\end{array}$ & CNR17 & Ulmus minor & $\begin{array}{l}\text { Libický luh, Velký Osek, } \\
\text { Czech Republic }\end{array}$ & Pepori 2012 & Yes, KF484897 \\
\hline $\begin{array}{l}\text { Geosmithia } \\
\text { species } 10\end{array}$ & CNR20 & Ulmus laevis & $\begin{array}{l}\text { Libický luh, Velký Osek, } \\
\text { Czech Republic }\end{array}$ & Pepori 2012 & Yes, KF484898 \\
\hline $\begin{array}{l}\text { Geosmithia } \\
\text { species } 10\end{array}$ & CNR21 & Ulmus glabra & $\begin{array}{l}\text { Nemetice, Czech } \\
\text { Republic }\end{array}$ & Pepori 2012 & Yes, KF484899 \\
\hline $\begin{array}{l}\text { Geosmithia } \\
\text { species } 10\end{array}$ & CNR32 & Ulmus laevis & $\begin{array}{l}\text { Středokluky, Czech } \\
\text { Republic }\end{array}$ & Pepori 2012 & Yes, KF484900 \\
\hline $\begin{array}{l}\text { Geosmithia } \\
\text { species } 10\end{array}$ & CNR41 & Ulmus minor & $\begin{array}{l}\text { Libický luh, Velký Osek, } \\
\text { Czech Republic }\end{array}$ & Pepori 2012 & Yes, KF484901 \\
\hline $\begin{array}{l}\text { Geosmithia } \\
\text { species } 10\end{array}$ & CNR69 & Ulmus glabra & $\begin{array}{l}\text { Hostenice, Czech } \\
\text { Republic }\end{array}$ & Pepori 2012 & Yes, KF484902 \\
\hline $\begin{array}{l}\text { Geosmithia } \\
\text { species } 10\end{array}$ & CNR71 & Ulmus glabra & $\begin{array}{l}\text { Březno u Loun, Czech } \\
\text { Republic }\end{array}$ & Pepori 2012 & Yes, KF484903 \\
\hline $\begin{array}{l}\text { Geosmithia } \\
\text { species } 10\end{array}$ & CNR72 & Ulmus laevis & $\begin{array}{l}\text { Dobřiň, Ústí nad Labem, } \\
\text { Czech Republic }\end{array}$ & Pepori 2012 & No \\
\hline $\begin{array}{l}\text { Geosmithia } \\
\text { species } 11\end{array}$ & $\begin{array}{l}\text { MK551 } \\
\text { (CCF3555) }\end{array}$ & $\begin{array}{l}\text { Scolytus intricatus on } \\
\text { Quercus pubescens }\end{array}$ & $\begin{array}{l}\text { Villányi hegy Mts., } \\
\text { Vokány, Hungary }\end{array}$ & Kolařík et al. 2008 & No \\
\hline $\begin{array}{l}\text { Geosmithia } \\
\text { species } 12\end{array}$ & $\begin{array}{l}\text { MK661 } \\
\text { (CCF3557) }\end{array}$ & $\begin{array}{l}\text { Leperisinus orni on } \\
\text { Fraxinus excelsior }\end{array}$ & $\begin{array}{l}\text { Balaton region, Szent } \\
\text { Győrgy hegy hill, } \\
\text { Hungary }\end{array}$ & Kolařík et al. 2008 & No \\
\hline $\begin{array}{l}\text { Geosmithia } \\
\text { species } 13\end{array}$ & MK1515a & $\begin{array}{l}\text { Pteleobius vittatus on } \\
\text { Ulmus minor }\end{array}$ & $\begin{array}{l}\text { Milovický les, Bulhary, } \\
\text { Czech Republic }\end{array}$ & Kolařík et al. 2008 & Yes, KF484904 \\
\hline $\begin{array}{l}\text { Geosmithia } \\
\text { species } 13\end{array}$ & MK924 & $\begin{array}{l}\text { Scolytus multistriatus on } \\
\text { Ulmus minor }\end{array}$ & $\begin{array}{l}\text { Hodonín, Bulhary, } \\
\text { Milovický les forest, } \\
\text { Czech Republic }\end{array}$ & Kolařík et al. 2008 & No \\
\hline $\begin{array}{l}\text { Geosmithia } \\
\text { species } 13\end{array}$ & MK963 & $\begin{array}{l}\text { Pteleobius vittatus on } \\
\text { Ulmus laevis }\end{array}$ & $\begin{array}{l}\text { Kančí obora forest, } \\
\text { Břeclav, Czech Republic }\end{array}$ & Kolarrík et al. 2008 & No \\
\hline $\begin{array}{l}\text { Geosmithia } \\
\text { species } 13\end{array}$ & $\begin{array}{l}\text { MK977 } \\
\left({ }^{C C F 3559{ }^{T}}\right)\end{array}$ & $\begin{array}{l}\text { Pteleobius vittatus on } \\
\text { Ulmus minor }\end{array}$ & $\begin{array}{l}\text { Milovický les, Bulhary, } \\
\text { Czech Republic }\end{array}$ & Kolarík et al. 2008 & No \\
\hline $\begin{array}{l}\text { Geosmithia } \\
\text { species } 13\end{array}$ & MK1856 & $\begin{array}{l}\text { Scolytus multistriatus on } \\
\text { Ulmus minor }\end{array}$ & $\begin{array}{l}\text { Sušice nad Otavou, } \\
\text { Czech Republic }\end{array}$ & Pepori 2012 & No \\
\hline $\begin{array}{l}\text { Geosmithia } \\
\text { langdonii }\end{array}$ & $\begin{array}{l}\text { MK1619 } \\
\text { (CCF4272) }\end{array}$ & $\begin{array}{l}\text { Bostrichid beetle on } \\
\text { Pistacia lentiscus }\end{array}$ & Sesimbra, Portugal & Kolařík et al. 2005 & No \\
\hline $\begin{array}{l}\text { Geosmithia } \\
\text { langdonii }\end{array}$ & MK1646 & $\begin{array}{l}\text { Scolytus multistriatus on } \\
\text { Ulmus laevis }\end{array}$ & $\begin{array}{l}\text { Neratovice, } \\
\text { Cerninovsko, Czech } \\
\text { Republic }\end{array}$ & Kolařík et al. 2005 & No \\
\hline $\begin{array}{l}\text { Geosmithia } \\
\text { langdonii }\end{array}$ & CNR11 & Ulmus minor & $\begin{array}{l}\text { Libický luh, Velký Osek, } \\
\text { Czech Republic }\end{array}$ & Pepori 2012 & Yes, KF484905 \\
\hline $\begin{array}{l}\text { Geosmithia } \\
\text { langdonii }\end{array}$ & CNR26 & Ulmus laevis & $\begin{array}{l}\text { Libický luh, Velký Osek, } \\
\text { Czech Republic }\end{array}$ & Pepori 2012 & No \\
\hline $\begin{array}{l}\text { Geosmithia } \\
\text { langdonii }\end{array}$ & CNR93 & Ulmus minor & $\begin{array}{l}\text { Žabokliky, Usti nad } \\
\text { Labem, Czech Republic }\end{array}$ & Pepori 2012 & No \\
\hline $\begin{array}{l}\text { Geosmithia } \\
\text { obscura }\end{array}$ & $\begin{array}{l}\text { MK616 } \\
\text { (CCF3425) }\end{array}$ & $\begin{array}{l}\text { Scolytus carpini on } \\
\text { Carpinus betulus }\end{array}$ & $\begin{array}{l}\text { Bakony range, Vinye } \\
\text { near of Fodöfö, Hungary }\end{array}$ & Kolařík et al. 2005 & No \\
\hline $\begin{array}{l}\text { Geosmithia } \\
\text { lavendula }\end{array}$ & $\begin{array}{l}\text { MK1781 } \\
\text { (CCF4285) }\end{array}$ & $\begin{array}{l}\text { Hypoborus ficus on Ficus } \\
\text { carica }\end{array}$ & $\begin{array}{l}\text { Baki Sahari, Baku, } \\
\text { Azerbaijan }\end{array}$ & Kolarrík et al. 2007 & No \\
\hline $\begin{array}{l}\text { Geosmithia } \\
\text { species } 20\end{array}$ & CNR132 & $\begin{array}{l}\text { Elm clone U'FL634' } \\
\text { (IPP-CNR) }\end{array}$ & Ugnano (FI) Italy & Pepori 2012 & Yes, KF484893 \\
\hline $\begin{array}{l}\text { Geosmithia } \\
\text { species } 21\end{array}$ & $\begin{array}{l}\text { MK1761 } \\
\text { (CCF4280) }\end{array}$ & $\begin{array}{l}\text { Hypoborus ficus on Ficus } \\
\text { carica }\end{array}$ & $\begin{array}{l}\text { Wadi al Furiáh, West } \\
\text { Bank, Israel }\end{array}$ & Kolařík et al. 2007 & No \\
\hline
\end{tabular}


Table 1 - (continued)

\begin{tabular}{|c|c|c|c|c|c|}
\hline Species & $\begin{array}{l}\text { Strain } \mathrm{N}^{\circ} \\
\text { (CCF code) }\end{array}$ & Source & Geographic origin & Reference & $\begin{array}{c}\text { Presence of cu gene, } \\
\text { GenBank Acc. } \mathrm{N}^{\circ}\end{array}$ \\
\hline $\begin{array}{l}\text { Geosmithia } \\
\text { species } 22\end{array}$ & $\begin{array}{l}\text { MK739 } \\
\text { (CCF3645) }\end{array}$ & $\begin{array}{l}\text { Phloetribus scarabeoides } \\
\text { on Olea europaea }\end{array}$ & Wadi al Mujib, Jordan & Kolařík et al. 2007 & No \\
\hline $\begin{array}{l}\text { Geosmithia } \\
\text { species } 23\end{array}$ & $\begin{array}{l}\text { MK781 } \\
\text { (CCF3639) }\end{array}$ & $\begin{array}{l}\text { Scolytus rugulosus on } \\
\text { Prunus armeniaca }\end{array}$ & $\begin{array}{l}\text { Demircili, Silifke, Içel } \\
\text { Province, Turkey }\end{array}$ & Kolařík et al. 2007 & No \\
\hline $\begin{array}{l}\text { Geosmithia } \\
\text { species } 25\end{array}$ & $\begin{array}{l}\text { MK1829a } \\
\text { (CCF4211) }\end{array}$ & $\begin{array}{l}\text { Cryphalus piceae on Abies } \\
\text { alba }\end{array}$ & $\begin{array}{l}\text { Pašínovice, Czech } \\
\text { Republic }\end{array}$ & $\begin{array}{l}\text { Kolařík \& } \\
\text { Jankowiak } 2013\end{array}$ & No \\
\hline $\begin{array}{l}\text { Geosmithia } \\
\text { species } 26\end{array}$ & $\begin{array}{l}\text { MK1828 } \\
\text { (CCF4293) }\end{array}$ & $\begin{array}{l}\text { Pityophthorus } \\
\text { pityographus on Pinus } \\
\text { sylvestris }\end{array}$ & $\begin{array}{l}\text { Sedlčany, Czech } \\
\text { Republic }\end{array}$ & $\begin{array}{l}\text { Kolařík \& } \\
\text { Jankowiak } 2013\end{array}$ & No \\
\hline $\begin{array}{l}\text { Geosmithia } \\
\text { species } 28\end{array}$ & $\begin{array}{l}\text { RJ279m } \\
\text { (CCF4210) }\end{array}$ & $\begin{array}{l}\text { Polygraphus polygraphus } \\
\text { on Picea abies }\end{array}$ & Chyszówki, Poland & $\begin{array}{l}\text { Kolařík \& } \\
\text { Jankowiak } 2013\end{array}$ & No \\
\hline $\begin{array}{l}\text { Geosmithia } \\
\text { species } 29\end{array}$ & $\begin{array}{l}\text { MK1809b } \\
\text { (CCF4199) }\end{array}$ & $\begin{array}{l}\text { Cryphalus piceae, } \\
\text { Pityophthorus } \\
\text { pityographus on Abies } \\
\text { alba }\end{array}$ & $\begin{array}{l}\text { Příběnice, Czech } \\
\text { Republic }\end{array}$ & $\begin{array}{l}\text { Kolařík \& } \\
\text { Jankowiak } 2013\end{array}$ & No \\
\hline $\begin{array}{l}\text { Geosmithia } \\
\text { species U316 }\end{array}$ & $\begin{array}{l}\text { U316 } \\
\text { (CCF4328) }\end{array}$ & $\begin{array}{l}\text { Bark beetle on Pinus } \\
\text { muricata }\end{array}$ & Monterey, CA, USA & M.K., unpubl. & No \\
\hline $\begin{array}{l}\text { Geosmithia } \\
\text { eupagioceri }\end{array}$ & CCF3754 & $\begin{array}{l}\text { Eupagiocerus dentipes on } \\
\text { Paullinia renesii }\end{array}$ & Heredia, Birrí, Costa Rica & $\begin{array}{l}\text { Kolařík \& } \\
\text { Kirkendall } 2010\end{array}$ & No \\
\hline $\begin{array}{l}\text { Geosmithia } \\
\text { microcorthyli }\end{array}$ & CCF3861 & $\begin{array}{l}\text { Microcorthylus species on } \\
\text { Cassia grandis }\end{array}$ & Heredia, Birrí, Costa Rica & $\begin{array}{l}\text { Kolařík \& } \\
\text { Kirkendall } 2010\end{array}$ & No \\
\hline $\begin{array}{l}\text { Geosmithia } \\
\text { rufescens }\end{array}$ & $\begin{array}{l}\text { MK1821 } \\
\text { (CCF4524) }\end{array}$ & $\begin{array}{l}\text { Cnesinus lecontei on } \\
\text { Croton draco }\end{array}$ & Heredia, Birrí, Costa Rica & $\begin{array}{l}\text { Kolařík \& } \\
\text { Kirkendall } 2010\end{array}$ & No \\
\hline $\begin{array}{l}\text { Geosmithia } \\
\text { morbida }\end{array}$ & 1259 & $\begin{array}{l}\text { Pityophthorus juglandis } \\
\text { on Juglans species }\end{array}$ & Oregon, USA & Kolařík et al. 2011 & No \\
\hline
\end{tabular}

MGB probes. Probe and primers were synthesized by the Custom TaqMan ${ }^{\circledR}$ Gene Expression Assay Service (Applied Biosystems by Life Technologies). The sequences of the primers and of the probe, which spanned the boundary between the first and the second exon, were as follows: cu-fwd $5^{\prime}$ TTGGTGTGGCCAATCTTGACT-3', cu-rev 5'-GGAACTGGCTGG GAGACGTA-3', cu-probe 5'-CCATGGCCCCCCAAGCGTG-3'. A reference calibration curve was set up with serial dilutions of cloned O. novo-ulmi cu cDNA. Total RNA was extracted from O. novo-ulmi isolate 182 mycelium, treated with DNase and the presence of contaminating genomic DNA assessed as described. A single-step RT-PCR (AccessQuick ${ }^{\text {TM }}$ RT-PCR System, Promega Corporation) was then carried out on $1 \mu \mathrm{g}$ of RNA with the following cu gene-specific primers: 5'AAATCTTCAAAATGCAGTTCTC-3' (forward) and 5'-CGAGCTTAAATGCCGACGGGGT-3' (reverse). Reactions were run on an agarose gel to check for the presence of a single band of the desired size ( $318 \mathrm{bp}$ ), which was cloned in the pCR ${ }^{\circledR} \mathrm{II}$ plasmid (TA Cloning Kit, Invitrogen by Life Technologies). The identity of the fragment was finally verified by sequencing.

Amplification reactions were run in triplicate in a 7300 Real Time PCR System (Applied Biosystems by Life Technologies) and contained $100 \mathrm{ng}$ cDNA, $1 \times$ TaqMan ${ }^{\circledR}$ Gene Expression Assay mix, and $1 \times$ TaqMan $^{\circledR}$ Universal PCR Master Mix. Thermocycling conditions were as recommended by the manufacturer. Each experiment was repeated at least twice. For all the experiments the threshold cycles were plotted against the $\log _{10}$ of the known standard amounts. Regression analysis was carried out to determine the equation of the line that best fitted the data and the regression coefficient $R^{2}$ values, which were comprised between 0.995 and 0.998 .

\section{Results and discussion}

\section{Occurrence of the cu gene in Geosmithia species}

Seventy Geosmithia strains representing 29 species (Table 1) were analysed for the presence of the cu gene by PCR with gene-specific primers as described in Section 2.2. Forty-six strains representing seven species were derived from insect vectors infesting elm trees or were isolated directly from decaying elm trees and 24 strains were obtained from insect vectors on plants other than elms. Fragments of the expected size (678 bp), corresponding to the entire sequence of the $\mathrm{cu}$ gene (454 bp) and including $224 \mathrm{bp}$ downstream to the translation stop codon, were obtained in 24 strains derived from elm trees $(52.1 \%)$ and sequenced. Amplification from fungi isolated from plants other than elms failed or gave bands of size different than expected. Some of these fragments were randomly chosen for sequencing and subjected to blastx searches, but in no case similarity to the cu gene was detected (Supplementary Material Table 1).

On the other hand, blastn searches for the Geosmithia cu sequences showed $100 \%$ identity to the Ophiostoma novo-ulmi cu gene (Accession nos. EU006082-EU006086,), and $99 \%$ identity to both O. novo-ulmi cu gene accession no. AJ295751 and the $\mathrm{cu}$ gene sequence from Geosmithia IVV7 (E-values 0.0). This was due, respectively, to the presence of a point mutation at an intron splice site in the O. novo-ulmi cu sequence (Pipe et al. 2000) and of two nucleotide substitutions in the IVV7 cu sequence: a $C$ to $G$ transversion at position +301 in the second exon and an $A$ to $G$ transition at position +384 in the second intron. The substitution in the coding region resulted in a Glu to 
Asp conservative change at position 75 in the primary sequence of the deduced protein.

Identity values between the cu gene sequences from Geosmithia spp. and the cu gene sequences from the other Ophiostoma spp. are reported in Supplementary Material (Table 2).

Ophiostoma cu sequences obtained from GenBank and the cu sequences from Geosmithia spp. were aligned and PhyML 3.0 was used to construct a phylogenetic tree, which showed that the Ophiostoma spp. formed distinct clusters and that the $\mathrm{cu}$ sequences from Geosmithia clustered with O. novo-ulmi (Fig 1). Taken together, these results demonstrated that the HGT event occurred between Geosmithia spp. and O. novoulmi. On this basis we propose that the HGT between the two fungi is very recent and ongoing around Europe. In fact, the strains harbouring the cu gene were isolated in Czech Republic, Italy, and Spain and belonged to Geosmithia spp. 2, 5, 10 , 13, 20, and Geosmithia langdonii (Table 1), coherently with the known distribution pattern of these species that are associated with phloeophagus bark beetles infesting broad-leaved trees in both the Mediterranean area and temperate Europe (Kolařík et al. 2007, 2008).

Our hypothesis of a very recent transfer of the cu gene between Geosmithia and O. novo-ulmi seemed in contradiction with the presence of two nucleotide substitutions in the $\mathrm{cu}$ gene sequence from Geosmithia sp. 5 strain IVV7, resulting in a slightly longer branch length in the phylogenetic tree (Fig 1). If the observed substitutions occurred in IVV7 after the transfer of the gene from 0 . novo-ulmi we must suppose this event to be much more ancient, $70 \mathrm{y}$ since the appearance of O. novo-ulmi in Europe being too short a time span for substitutions to occur. However, data on the appearance of $O$. novo-ulmi in Europe allowed to rule out the possibility that the transfer of the cu gene happened earlier than 1940s, since all Ophiostoma strains isolated before 1940s are Ophiostoma ulmi (Brasier 1991). An alternative scenario could be that the observed substitutions were already present in the $c u$ gene in the O. novo-ulmi isolate involved in the HGT event with IVV7. The possibility of the existence of variant forms of the

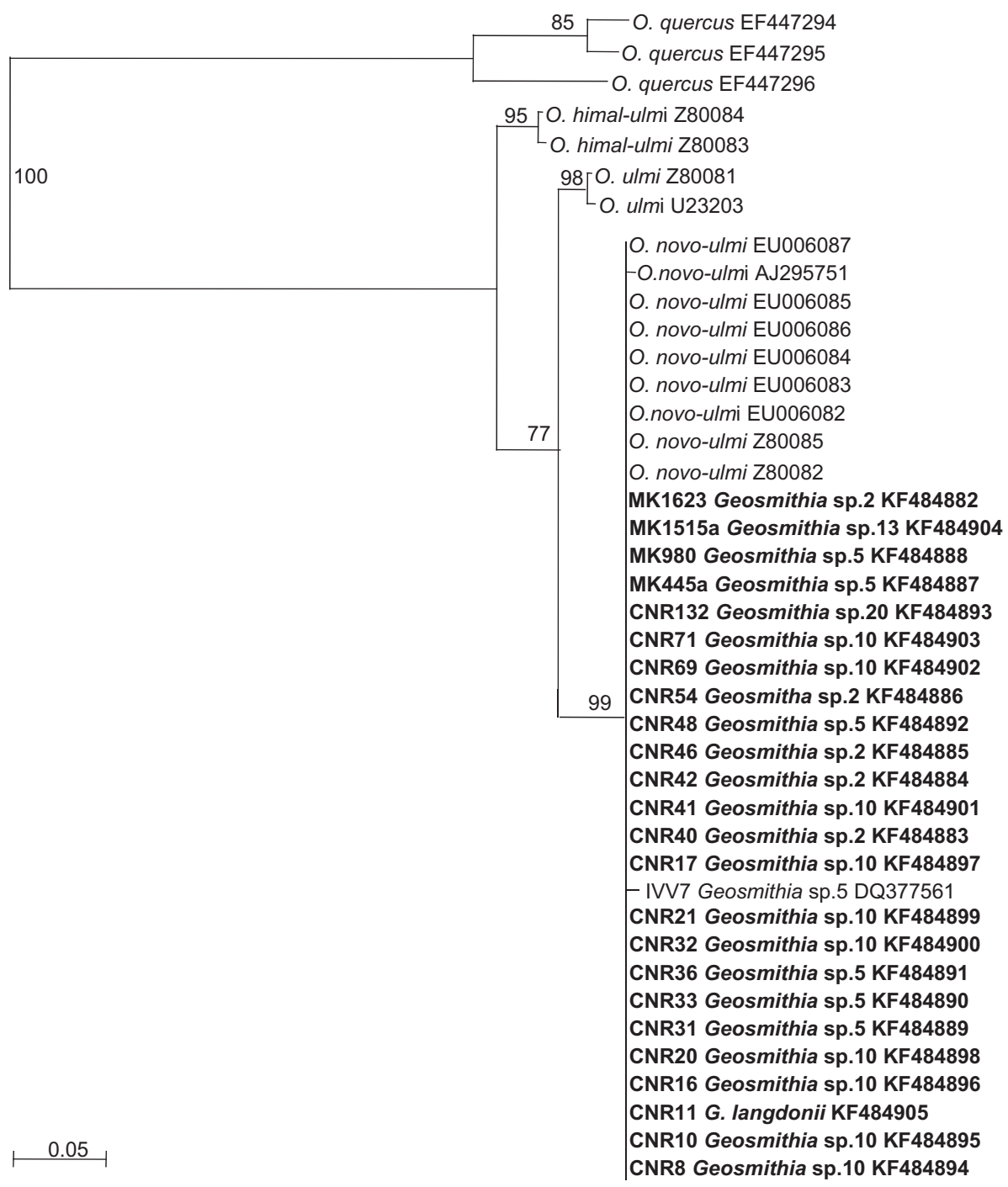

Fig 1 - ML tree based on the aligned cu gene sequences from 0. ulmi, 0. novo-ulmi, 0. himal-ulmi, O. quercus, and Geosmithia spp. (in bold). GenBank accession numbers are indicated for each sequence. Phylogenetic tree was constructed with PhyML 3.0 performing bootstrap analysis with 500 replicates. The cu gene sequences from 0 . quercus were used as outgroup. 
cu gene is sustained by the report by Pipe et al. (2000) of a 0 . novo-ulmi strain whose cu gene had a mutation in an intron splice site.

Finally, intraspecies variability was observed in Geosmithia spp. in terms of the presence or absence of the cu gene, which was found in five out of eight strains of Geosmithia sp. 2, six out of nine strains of Geosmithia sp. 5, ten out of 17 strains of Geosmithia sp. 10, one out of five strains of Geosmithia sp. 13, and G. langdonii. In order to explain this observation we propose that multiple and independent HGT events occurred between 0 . novo-ulmi and Geosmithia spp., favoured by the close proximity of the two fungi as a consequence of habitat sharing. These HGT events could involve different $O$. novo-ulmi genomic fragments, not necessarily comprising the cu gene. The absence of the cu gene in some Geosmithia strains could therefore be accounted for by two possibilities: (i) these strains could harbour other fragments of the O. novo-ulmi genome, even if the very high frequency of the cu gene in Geosmithia suggests that the transferred region is not completely random, or (ii) they were not involved in HGT. The lack of information concerning Geosmithia genomes does not allow at present to verify this hypothesis.

\section{Expression of the cu gene in Geosmithia species}

In order to assess if the cu gene was functional in Geosmithia, its expression level was evaluated by real time PCR. As a first step a time-course was set up on our reference species Geosmithia sp. 5 strain IVV7 by growing the fungus in liquid culture for 4, 8, 12, 16, and $20 \mathrm{~d}$. Results showed that the cu mRNA was present in strain IVV7, albeit in an extremely low amount, from day 8 to the end of the experiment, the maximum being reached after $8 \mathrm{~d}$ of growth (73.4 ag of cu mRNA $\mu \mathrm{g}^{-1}$ total RNA) (Fig 2A). The quantity of cu mRNA in Ophiostoma novo-ulmi isolate 182 after $4 \mathrm{~d}$ of growth in the same conditions was $67 \mathrm{fg}_{\mu \mathrm{g}} \mathrm{g}^{-1}$ total RNA, thus about 1000-fold higher than the highest level reached in strain IVV7. The same time-point was therefore used to analyse $c u$ gene expression in eight strains belonging to the species where the gene was found, i.e. Geosmithia sp. 2 (CNR46), Geosmithia sp. 5 (MK980 and CNR36), Geosmithia sp. 10 (CNR32 and CNR71), Geosmithia sp. 13 (MK1515a), Geosmithia sp. 20 (CNR132), and Geosmithia langdonii (CNR11). cu mRNA was detected in all the strains tested, its amount being variable with respect to the reference species (Fig 2B). The amount of cu mRNA in all the strains tested was always in the same quantitative range as in strain IVV7, thus showing that the nucleotide substitutions present in the IVV7 cu gene did not affect its expression. However, in the strain CNR36 the quantity of cu mRNA was so low as to be negligible.

The fungi of the genus Geosmithia used in this study were endophytic organisms that lived in the galleries built by subcorticolous bark beetles inside decaying elm trees showing DED symptoms. Ophiostoma novo-ulmi is known to be present in the microbiota associated with insect galleries (Kolařík et al. 2011), as shown also in other instances (Kolařík et al. $2007,2008)$. To test if growing Geosmithia in conditions more similar to its natural habitat could increase the expression of the cu gene, Geosmithia sp. 5 strain IVV7 was grown for 4, 6,8 , and $12 \mathrm{~d}$ on medium containing elm sawdust and in dual culture with 0 . novo-ulmi isolate 182. Results obtained
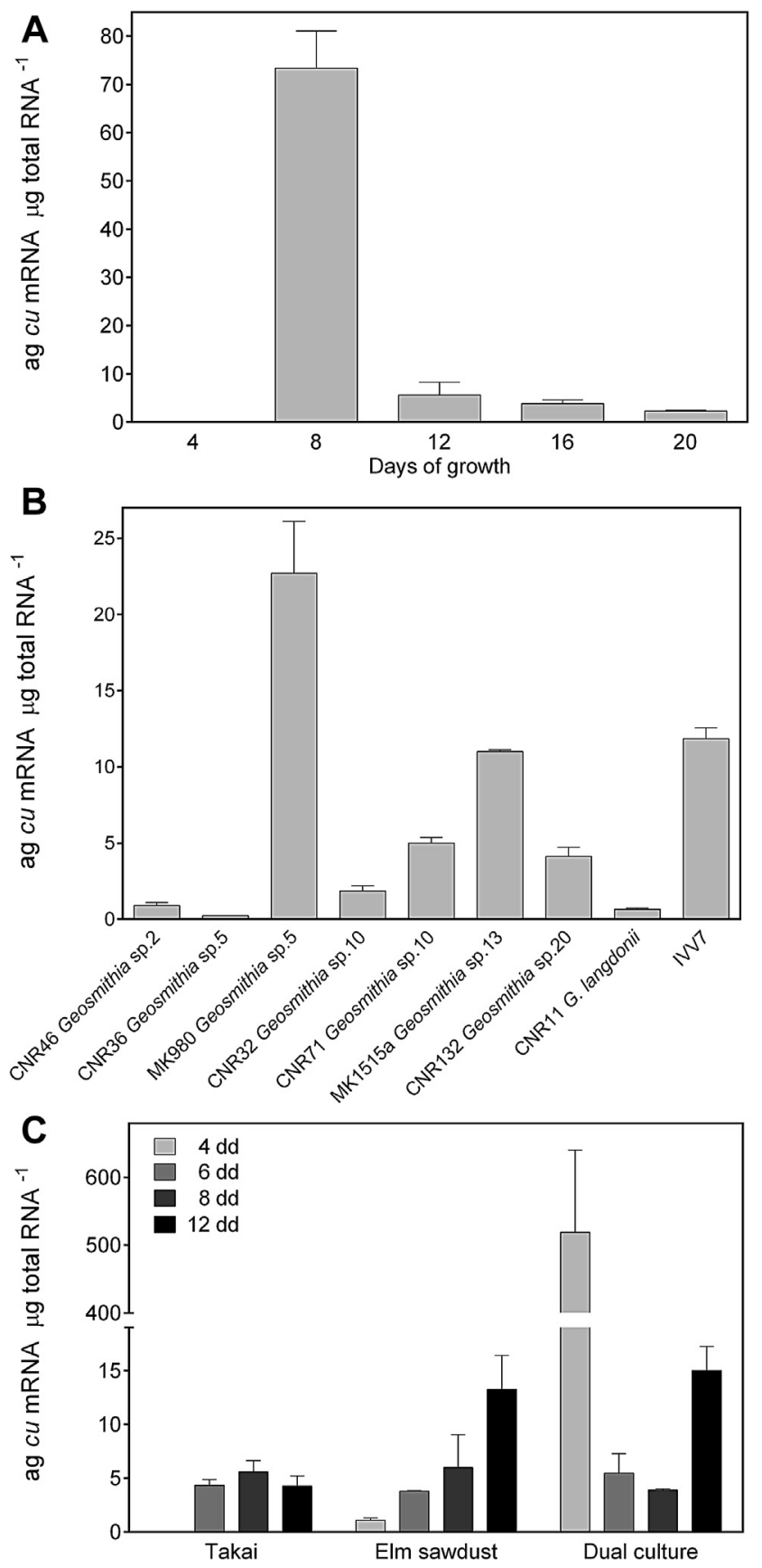

Fig 2 - cu gene expression in Geosmithia spp. as determined by real time PCR. (A) cu mRNA in Geosmithia sp. 5 strain IVV7 after 4, 8, 12, 16, and $20 \mathrm{~d}$ of growth in liquid culture; (B) cu mRNA in Geosmithia spp. 2 (strain CNR46), 5 (strains MK980 and CNR36), 10 (strains CNR32 and CNR71), 13 (strain MK1515a), 20 (CNR132), and G. langdonii (strain CNR11) after $8 \mathrm{~d}$ of growth in liquid culture. The reference species Geosmithia sp. 5 strain IVV7 was used as a control; (C) cu mRNA in Geosmithia sp. 5 strain IVV7 after 4, 6, 8, and $12 \mathrm{~d}$ of growth on solid Takai medium, on medium containing elm sawdust, and in dual culture with 0 . novo-ulmi. Gene expression was indicated as attograms (ag) of cu mRNA $\mu \mathrm{g}^{-1}$ of total RNA. 
showed that on elm sawdust the amount of cu mRNA was increased by about three-fold, and by 100-fold after $4 \mathrm{~d}$ of dual culture, in comparison to the average value for control grown on solid Takai medium (Fig 2C). The level of cu mRNA remained in all cases very low also with respect to $O$. novoulmi grown for $4 \mathrm{~d}$ on solid Takai medium (0.72 pg cu mRNA $\mu \mathrm{g}^{-1}$ total RNA). To exclude any contamination of the RNA samples from strain IVV7 by 0 . novo-ulmi, the one having the highest cu mRNA content ( $4 \mathrm{~d}$ of dual culture) was reverse transcribed and the ITS region of the rDNA cistron was amplified with the universal primers ITS1 and ITS4 (White et al. 1990). The amplicon size difference allowed to distinguish the two species, being approximately $650 \mathrm{bp}$ and $560 \mathrm{bp}$ for O. novo-ulmi and Geosmithia pallida, respectively. No band corresponding to the size of Ophiostoma ITS was found in the IVV7 sample after 50 cycles of amplification (Fig 3). Moreover, sequencing of the RT-PCR product showed that the ITS sequence amplified was only that of strain IVV7, demonstrating that no Ophiostoma RNA was present in the original sample.

The cu expression levels detected in Geosmithia were much lower than those reported for O. novo-ulmi (Tadesse et al. 2003), thus raising the question of the functional significance of $\mathrm{cu}$ mRNA in the former species. The genomic fragment transferred between O. novo-ulmi and Geosmithia comprised $317 \mathrm{bp}$ upstream to the coding sequence (Bettini et al. 2010), a region where several putative regulatory motifs are present (Carresi et al. 2008). On this basis it could be hypothesized that the Geosmithia transcriptional machinery recognized the regulatory region of the Ophiostoma gene, even if with scarce efficiency. The conservation of the cu gene sequence in Geosmithia could

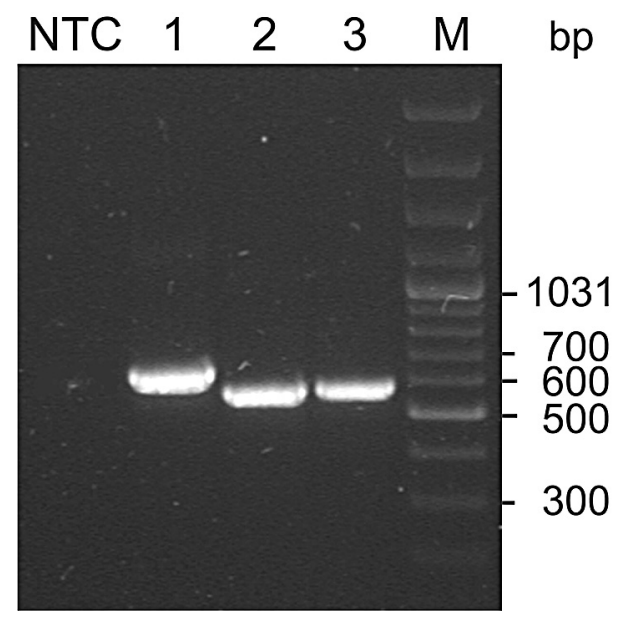

Fig 3 - Test for contamination of Geosmithia sp. 5 strain IVV7 samples from dual culture with 0 . novo-ulmi. RNA extracted from strain IVV7 after $4 \mathrm{~d}$ of cocultivation was reverse transcribed and PCR was carried out with universal primers ITS1 and ITS4. Amplifications with 0 . novo-ulmi and strain IVV7 DNA were carried out as controls. NTC, no template control; lane 1, 0. novo-ulmi DNA; lane 2, Geosmithia sp. 5 strain IVV7 DNA; lane 3, Geosmithia sp. 5 strain IVV7 cDNA, $4 \mathrm{~d}$ of dual culture; M, GeneRuler $100 \mathrm{bp}$ DNA Ladder Plus (Fermentas, Thermo Scientific Molecular Biology). therefore be a consequence of the very recent transfer rather than reflect the presence of selective constraints on a functional sequence.

The HGT event involving the $\mathrm{cu}$ gene happened with very high frequency, as $52.1 \%$ of the Geosmithia strains isolated from elm trees were found to possess the gene. A similar frequency was reported by Coelho et al. (2013) for the horizontal transfer of the fructose transporter gene FSY1, that was present in 109 fungal genomes over 241 analysed. However in this case, as in most reports of HGT, there is an immediate advantage for the recipient species from the acquirement of the foreign gene. In our case this is less evident, also because strain IVV7 had recently been shown to possess a previously unidentified class II hydrophobin, GEO1 (Bettini et al. 2012). In conclusion, the cu gene could be a marker of more extensive transfers of genetic material, as documented in other fungi.

In spite of the growing number of HGTs described in fungi the mechanisms underlying the transfer and the integration of genetic material in the recipient genomes remain obscure, except for a few cases. Formation of transient hyphal or conidial anastomoses, direct uptake of DNA, presence of mobile elements in the vicinity of the transferred sequence and recombination have been proposed (Mehrabi et al. 2011; Richards et al. 2011; Fitzpatrick 2012). Richards et al. (2009) showed that in two gene transfers from a fungus to the bryophyte moss Physcomitrella patens, the HGT was located near to a putative transposable element. In other instances the transferred sequence was found in the subtelomeric regions of chromosomes, characterized by frequent rearrangements and rich in transposable elements (Coelho et al. 2013). On the other hand, homologous recombination was involved in the transfer of genetic material between the yeast wine strain Saccharomyces cerevisiae EC1118 and Zygosaccharomyces bailii (Novo et al. 2009) and of the penicillin biosynthetic gene cluster in Penicillium chrysogenum (Rosewich \& Kistler 2000).

In order to assess if transposable elements were present in the regions flanking the $\mathrm{cu}$ gene, that could account for its transfer between $\mathrm{O}$. novo-ulmi and Geosmithia spp., we took advantage of the recently published genome sequence of $O$. novoulmi (Forgetta et al. 2013). Firstly, a blastn search was performed to identify the sequence containing the cu gene, which was found in the genomic scaffold scaffold00002 (GenBank acc. no. KB209922). A second blastn search on the scaffold00002 revealed two sequences with 99 and $95 \%$ identity (E-values 0.0), respectively, to 0 . novo-ulmi transposons OPHIO1 and OPHIO3 (Bouvet et al. 2007) located about 500 and $700 \mathrm{kbp}$ from the $3^{\prime}$ end of the cu gene. However, due to the large distance between these elements and the $c u$ gene, their involvement in the gene transfer event could be excluded.

The high frequency of cu gene transfer between 0 . novoulmi and Geosmithia spp. suggested the establishment of a closer relationship between the two species beyond simple habitat sharing inside elm trees. Interestingly, rare interspecific sexual crosses were demonstrated in O. novo-ulmi to be involved in the acquirement of mating type and vegetative incompatibility genes from Ophiostoma ulmi (Paoletti et al. 2006), and the induction of sterile perithecia production was stimulated in dual culture of our reference species Geosmithia sp. 5 strain IVV7 and O. novo-ulmi cultures mating type B 
strains (Pepori 2012). Further work is underway in our laboratories to assess the possible mechanism for gene transfer between Geosmithia spp. and O. novo-ulmi.

\section{Conflict of interest}

The authors declare that they have no conflict of interest.

\section{Acknowledgements}

This work is dedicated to the memory of our dear and highly esteemed friend and colleague Giovanni Del Sorbo. Research funded by the Ministero Italiano dell'Università e della Ricerca Scientifica (MIUR), Progetti di Ricerca di Interesse Nazionale 2009 to A. Scala. M. Kolařík was supported by the grant GACR (_501100001824) P506/11/2302.

\section{Appendix A. Supplementary data}

Supplementary data related to this article can be found at http://dx.doi.org/10.1016/j.funbio.2014.04.007.

\section{RE FERENCES}

Aguileta G, Hood ME, Refrégier G, Giraud T, 2009. Genome evolution in plant pathogenic and symbiotic fungi. In: Kader J-C, Delseny M (eds), Advances in Botanical Research. Academic Press, pp. 151-193.

Aimanianda V, Bayry J, Bozza S, Kniemeyer O, Perruccio K, Elluru SR, Clavaud C, Paris S, Brakhage AA, Kaveri SV, Romani L, Latgé J-P, 2009. Surface hydrophobin prevents immune recognition of airborne fungal spores. Nature 460: 1117-1121.

Akagi Y, Akamatsu H, Otani H, Kodama M, 2009. Horizontal chromosome transfer, a mechanism for the evolution and differentiation of a plant-pathogenic fungus. Eukaryotic Cell 8 : 1732-1738.

Altschul SF, Gish W, Miller W, Myers EW, Lipman DJ, 1990. Basic local alignment search tool. Journal of Molecular Biology 215: 403-410.

Andersson JO, Sjögren AM, Davis LAM, Embley TM, Roger AJ, 2003. Phylogenetic analyses of diplomonad genes reveal frequent lateral gene transfers affecting eukaryotes. Current Biology 13: 94-104.

Baccelli I, Comparini C, Bettini PP, Martellini F, Ruocco M, Pazzagli L, Bernardi R, Scala A, 2012. The expression of the cerato-platanin gene is related to hyphal growth and chlamydospores formation in Ceratocystis platani. FEMS Microbiology Letters 327: 155-163.

Bettini P, Carresi L, Comparini C, Pazzagli L, Pepori AL, Santini A, Cappugi G, Scala F, Scala A, 2010. Study of two different hydrophobins in Geosmithia spp. Journal of Plant Pathology 92 (Supplement 4): S4.73.

Bettini PP, Frascella A, Comparini C, Carresi L, Pepori AL, Pazzagli L, Cappugi G, Scala F, Scala A, 2012. Identification and characterization of GEO1, a new class II hydrophobin from Geosmithia spp. Canadian Journal of Microbiology 58: 965-972.
Bock R, 2010. The give-and-take of DNA: horizontal gene transfer in plants. Trends in Plant Science 15: 11-22.

Boto L, 2010. Horizontal gene transfer in evolution: facts and challenges. Proceedings of the Royal Society B 277: 819-827.

Bouvet GF, Jacobi V, Bernier L, 2007. Characterization of three transposons in the Dutch elm disease fungi and evidence of repeat-induced point (RIP) mutations. Fungal Genetics and Biology 44: 430-443.

Bowden CG, Smalley E, Guries RP, Hubbes M, Temple B, Horgen PA, 1996. Lack of association between cerato-ulmin production and virulence in Ophiostoma novo-ulmi. Molecular Plant Microbe Interactions 9: 556-564.

Bowler C, Allen AE, Badger JH, et al., 2008. The Phaeodactylum genome reveals the evolutionary history of diatom genomes. Nature 456: 239-244.

Brasier CM, 1991. Ophiostoma novo-ulmi sp. nov., causative agent of current Dutch elm disease pandemics. Mycopathologia 115: 151-161.

Brasier CM, Buck KW, 2001. Rapid evolutionary changes in a globally invading fungal pathogen (Dutch elm disease). Biological Invasions 3: 223-233.

Brasier CM, Kirk SA, 2001. Designation of the EAN and NAN races of Ophiostoma novo-ulmi as subspecies. Mycological Research 105: $547-554$.

Brasier CM, Kirk SA, 2010. Rapid emergence of hybrids between the two subspecies of Ophiostoma novo-ulmi with a high level of pathogenic fitness. Plant Pathology 59: 186-199.

Brasier CM, Kirk SA, Tegli S, 1995. Naturally occurring non ceratoulmin producing mutants of Ophiostoma novo-ulmi are pathogenic but lack aerial mycelium. Mycological Research 99: 436-440.

Brasier CM, Mehrotra MD, 1995. Ophiostoma himal-ulmi sp. nov., a new species of Dutch elm disease fungus endemic to the Himalayas. Mycological Research 99: 205-215.

Carresi L, Comparini C, Bettini PP, Pazzagli L, Cappugi G, Scala F, Scala A, 2008. Isolation of the orthologue of the cerato-ulmin gene in Ophiostoma quercus and characterization of the purified protein. Mycological Research 112: 1245-1255.

Coelho MA, Gonçalves C, Sampaio JP, Gonçalves P, 2013. Extensive intra-kingdom horizontal gene transfer converging on a fungal fructose transporter gene. PLOS Genetics 9: e1003587.

Del Sorbo G, Scala F, Parrella G, Lorito M, Comparini C, Ruocco M, Scala A, 2000. Functional expression of the gene $\mathrm{cu}$, encoding the phytotoxic hydrophobin cerato-ulmin, enables Ophiostoma quercus, a non-pathogen on elm, to cause symptoms of Dutch elm disease. Molecular Plant Microbe Interactions 13: 43-53.

Dunning Hotopp JC, 2011. Horizontal gene transfer between bacteria and animals. Trends in Genetics 27: 157-163.

Fitzpatrick DA, 2012. Horizontal gene transfer in fungi. FEMS Microbiology Letters 329: 1-8.

Forgetta V, Leveque G, Dias J, Grove D, Lyons Jr R, Genik S, Wright C, Singh S, Peterson N, Zianni M, Kieleczawa J, Steen R, Perera A, Bintzler D, Adams S, Hintz W, Jacobi V, Bernier L, Levesque R, Dewar K, 2013. Sequencing of the Dutch elm disease fungus genome using the Roche/454 GS-FLX Titanium System in a comparison of multiple genomics core facilities. Journal of Biomolecular Techniques 24: 39-49.

Friesen TI, Stukenbrock EH, Liu Z, Meinhardt S, Ling H, Faris JD, Rasmussen JB, Solomon PS, McDonald BA, Oliver RP, 2006. Emergence of a new disease as a result of interspecific virulence gene transfer. Nature Genetics 38: 953-956.

Fuchs U, Czymmek KJ, Sweigard JA, 2004. Five hydrophobin genes in Fusarium verticillioides include two required for microconidial chain formation. Fungal Genetics and Biology 41: 852-864.

Gardiner DM, Kazan K, Manners JM, 2013. Cross-kingdom gene transfer facilitates the evolution of virulence in fungal pathogens. Plant Science 210: 151-158. 
Gogarten P, Townsend JP, 2005. Horizontal gene transfer, genome innovation and evolution. Nature Reviews Microbiology 3: 679-687.

Gojkovic Z, Knecht W, Zameitat E, Warneboldt J, Coutelis J-B, Pynyaha Y, Neuveglise C, Moller K, Löffler M, Piskur J, 2004. Horizontal gene transfer promoted evolution of the ability to propagate under anaerobic conditions in yeasts. Molecular Genetics and Genomics 271: 387-393.

Grobbelaar JW, Aghayeva DN, de Beer ZW, Bloomer P, Wingfield MJ, Wingfield BD, 2009. Delimitation of Ophiostoma quercus and its synonyms using multiple gene phylogenies. Mycological Progress 8: 221-236.

Guindon S, Dufayard JF, Lefort V, Anisimova M, Hordijk W, Gascuel O, 2010. New algorithms and methods to estimate maximum-likelihood phylogenies: assessing the performance of PhyML 3.0. Systematic Biology 59: 307-321.

Karlsson M, Stenlid J, Olson A, 2007. Two hydrophobin genes from the conifer pathogen Heterobasidion annosum are expressed in aerial hyphae. Mycologia 99: 227-231.

Katoh K, Toh H, 2008. Recent developments in the MAFFT multiple sequence alignment program. Briefings in Bioinformatics 9: 286-298.

Keeling PJ, Palmer JD, 2008. Horizontal gene transfer in eukaryotic evolution. Nature Reviews Genetics 9: 605-618.

Kim S, Ahn I-P, Rho H-S, Lee Y-H, 2005. MHP1, a Magnaporthe grisea hydrophobin gene, is required for fungal development and plant colonization. Molecular Microbiology 57: 1224-1237.

Klimes A, Amyotte SG, Grant S, Kang S, Dobinson KF, 2008. Microsclerotia development in Verticillium dahliae: regulation and differential expression of the hydrophobin gene VDH1. Fungal Genetics and Biology 45: 1525-1532.

Kolařík M, Freeland M, Utlet C, Tisserat N, 2011. Geosmithia morbida sp. nov., a new phytopathogenic species living in symbiosis with the walnut twig beetle (Pityophthorus juglandis) on Juglans in USA. Mycologia 103: 325-332.

Kolař́k M, Jankowiak R, 2013. Vector affinity and diversity of Geosmithia fungi living on subcortical insects inhabiting Pinaceae species in central and northeastern Europe. Microbial Ecology 66: $682-700$.

Kolařík M, Kirkendall LR, 2010. Evidence for a new lineage of primary ambrosia fungi in Geosmithia Pitt (Ascomycota: Hypocreales). Fungal Biology 114: 679-689.

Kolař́k M, Kostovík M, Pažoutová S, 2007. Host range and diversity of the genus Geosmithia (Ascomycota: Hypocreales) living in association with bark beetles in the Mediterranean area. Mycological Research 111: 1298-1310.

Kolařík M, Kubátová A, Čepika I, Pažoutová S, Šrůtka P, 2005. A complex of three new white-spored, sympatric, and host range limited Geosmithia species. Mycological Research 109: 1323-1336.

Kolařík M, Kubátová A, Hulcr J, Pažoutová S, 2008. Geosmithia fungi are highly diverse and consistent bark beetle associates: evidence from their community structure in temperate Europe. Microbial Ecology 55: 65-80.

Kolařík M, Kubátová A, Pažoutová S, Šrůtka P, 2004. Morphological and molecular characterization of Geosmithia putterillii, G. pallida comb. nov. and G. flava sp. nov., associated with subcorticolous insects. Mycological Research 108: 1053-1069.

Ma L-J, van der Does HC, Borkovich KA, et al., 2010. Comparative genomics reveals mobile pathogenicity chromosomes in Fusarium. Nature 464: 367-373.

Mankel A, Krause K, Kothe E, 2002. Identification of a hydrophobin gene that is developmentally regulated in the ectomycorrhizal fungus Tricholoma terreum. Applied and Environmental Microbiology 68: 1408-1413.

Mehrabi R, Bahkali AH, Abd-Elsalam KA, Moslem M, Ben M’Barek S, Mirzadi Gohari A, Karimi Jashni M, Stergiopoulos I,
Kema GHJ, de Wit PJGM, 2011. Horizontal gene and chromosome transfer in plant pathogenic fungi affecting host range. FEMS Microbiology Reviews 35: 542-544.

Novo M, Bigey F, Beyne E, Galeote V, Gavory F, Mallet S, Cambon B, Legras J-L, Wincker P, Casaregola S, Dequin S, 2009. Eukaryote-to-eukaryote gene transfer events revealed by the genome sequence of the wine yeast Saccharomyces cerevisiae EC1118. Proceedings of the National Academy of Sciences USA 106: 16333-16338.

Ochman H, Lawrence JG, Groisman E, 2000. Lateral gene transfer and the nature of bacterial innovation. Nature 405: 299-304.

Oliver RP, Solomon PS, 2008. Recent fungal diseases of crop plants: is lateral gene transfer a common theme? Molecular Plant Microbe Interactions 21: 287-293.

Paoletti M, Buck KW, Brasier CM, 2006. Selective acquisition of novel mating type and vegetative incompatibility genes via interspecies gene transfer in the globally invading eukaryote Ophiostoma novo-ulmi. Molecular Ecology 15: 249-262.

Pepori AL, 2012. Caratterizzazione e ruolo delle comunità di Geosmithia spp. su olmo Ph.D. thesis. University of Florence.

Pipe ND, Brasier CM, Buck KW, 2000. Two natural cerato-ulmin (CU)-deficient mutants of Ophiostoma novo-ulmi: one has an introgressed O. ulmi cu gene, the other has an O. novo-ulmi cu gene with a mutation in an intron splice consensus sequence. Molecular Plant Pathology 1: 379-382.

Ricard G, McEwan NR, Dutilh BE, Jouany J-P, Macheboeuf D, Mitsumori M, McIntosh FM, Michalowski T, Nagamine T, Nelson N, Newbold CJ, Nsabimana E, Takenaka A, Thomas NA, Ushida K, Hackestein JHP, Huynen MA, 2006. Horizontal gene transfer from bacteria to rumen ciliates indicates adaptation to their anaerobic, carbohydrates-rich environment. BMC Genomics 7: 22 .

Richards TA, Soanes DM, Jones MDM, Vasieva O, Leonard G, Paszkiewicz K, Foster PG, Hall N, Talbot NJ, 2011. Horizontal gene transfer facilitated the evolution of plant parasitic mechanisms in the oomycetes. Proceedings of the National Academy of Sciences USA 108: 15258-15263.

Richards TA, Soanes TM, Foster PG, Leonard G, Thornton CR, Talbot NJ, 2009. Phylogenomic analysis demonstrates a pattern of rare and ancient horizontal gene transfer between plants and fungi. The Plant Cell 21: 1897-1911.

Richards WC, 1993. Cerato-ulmin: a unique wilt toxin of instrumental significance in the development of Dutch elm disease. In: Sticklen NB, Sherald JL (eds), Dutch Elm Disease Research, Cellular and Molecular Approaches. Springer-Verlag New York Inc., pp. 89-151.

Rosewich LU, Kistler HC, 2000. Role of horizontal gene transfer in the evolution of fungi. Annual Reviews of Phytopathology 38: 325-363.

Scala A, Tegli S, Comparini C, Mittempergher L, Scala F, Del Sorbo G, 1994. Influence of fungal inoculum on cerato-ulmin production; purification of cerato-ulmin and detection in elm sucker cuttings. Petria 4: 57-67.

Scala F, Bertelli E, Coppola L, Del Sorbo G, Tegli S, Scala A, 1997. Comparative determination of cerato-ulmin on cell surface and in mycelial extracts of pathogenic and non-pathogenic Ophiostoma species. Mycological Research 101: 829-834.

Scherrer S, De Vries OM, Dudler R, Wessels JG, Honegger R, 2000. Interfacial self-assembly of fungal hydrophobins of the lichenforming ascomycetes Xanthoria parietina and X. ectaneoides. Fungal Genetics and Biology 30: 81-93.

Schönknecht G, Chen W-H, Ternes CM, Barbier GG, Shreshta RP, Stanke M, Bräutigam A, Baker BJ, Banfield JF, Garavito RM, Carr K, Wilkerson C, Rensing SA, Gagneul D, Dickenson NE, Oesterhelt C, Lercher MJ, Weber APM, 2013. Gene transfer from bacteria and archaea facilitated evolution of an extremophilic eukaryote. Science 339: 1207-1210. 
Slot JC, Rokas A, 2011. Horizontal transfer of a large and highly toxic secondary metabolic gene cluster between fungi. Current Biology 21: 134-139.

Sutherland ML, Mittempergher L, Brasier CM, 1995. Control of Dutch elm disease by induced host resistance. European Journal of Forest Pathology 25: 307-318.

Svircev AM, Jeng RS, Hubbes M, 1988. Detection of cerato-ulmin on aggressive isolates of Ophiostoma ulmi by immunochemistry and scanning electron microscopy. Phytopathology 78: 322-327.

Tadesse Y, Bernier L, Hintz WE, Horgen PA, 2003. Real time RTPCR quantification and Northern analysis of cerato-ulmin (CU ) gene transcription in different strains of the phytopathogens Ophiostoma ulmi and O. novo-ulmi. Molecular Genetics and Genomics 269: 789-796.

Takai S, 1974. Pathogenicity and cerato-ulmin production in Ceratocystis ulmi. Nature 252: 124-126.

Talbot NJ, 2003. On the trail of a cereal killer: exploring the biology of Magnaporthe grisea. Annual Reviews of Microbiology 57: 177-202.

Tamura K, Peterson D, Peterson N, Stecher G, Nei M, Kumar S, 2011. MEGA5: molecular evolutionary genetics analysis using maximum likelihood, evolutionary distance, and maximum parsimony methods. Molecular Biology and Evolution 28: 2731-2739.

Tegli S, Scala A, 1996. Isolation and characterization of non cerato-ulmin producing laboratory induced mutants of Ophiostoma novo-ulmi. Mycological Research 100: 661-668.
Temple B, Horgen PA, 2000. Biological roles for cerato-ulmin, a hydrophobin secreted by the elm pathogens, Ophiostoma ulmi and O. novo-ulmi. Mycologia 92: 1-9.

Temple B, Horgen PA, Bernier L, Hintz WE, 1997. Cerato-ulmin, a hydrophobin secreted by the causal agents of Dutch elm disease, is a parasitic fitness factor. Fungal Genetics and Biology 22: $39-53$.

van Wetter MA, Wösten HAB, Sietsma JH, Wessels JGH, 2000. Hydrophobin gene expression affects hyphal wall composition in Schizophyllum commune. Fungal Genetics and Biology 31: 99-104.

White TJ, Bruns T, Lee S, Taylor J, 1990. Amplification and direct sequencing of fungal ribosomal RNA genes for phylogenetics. In: Innis MA, Gelfand DH, Sninsky JJ, White TJ (eds), PCR Protocols: a guide to methods and applications. Academic Press Inc., New York, pp. 315-322.

Whiteford JR, Spanu PD, 2002. Hydrophobins and the interactions between fungi and plants. Molecular Plant Pathology 3: 391-400.

Wösten HAB, 2001. Hydrophobins: multipurpose proteins. Annual Reviews of Microbiology 55: 625-646.

Yamada M, Sakuraba S, Shibata K, Inatomi S, Okazaki M, Shimosaka M, 2005. Cloning and characterization of a gene coding for a hydrophobin, Fv-hyd1, specifically expressed during fruiting body development in the basidiomycete Flammulina velutipes. Applied Microbiology and Biotechnology 67: $240-246$. 